\title{
Termination of pregnancy: Patients' perceptions of care
}

Pauline Slade, BSc, MSc, PhD, FBPsS, Reader in Clinical Psychology/Consultant Clinical Psychologist; Sarah Heke, BA, Psychology Assistant; Joanne Fletcher, RGN, BA, MA, Nurse Practitioner, Peter Stewart, MA, BM, BCL, FRCOG, Consultant in Obstetrics and Gynaecology, Department of Psychology, University of Sheffield and Northern General Hospital, Sheffield, UK

Correspondence: $\operatorname{Dr}$ P Slade, Reader in Clinical Psychology/Consultant Clinical Psychologist for Community Health Sheffield, Clinical Psychology Unit, Department of Psychology, The University of Sheffield, Western Bank, Sheffield S10 2 TP, UK. Tel: 0114222 6568, Fax: 0114222 6610, email: p.slade@sheffield.ac.uk

(Accepted August $31^{\text {st }}, 2000$ )

\begin{abstract}
Summary
Background. Little is known about women's perceptions of care in termination of pregnancy (TOP). Developing an understanding of how care is experienced is crucial to improvements in services.

Method. Two hundred and eight women undergoing either a medical or surgical TOP reported on their perspectives of the experience and the care received. A mix of questionnaire and open questions analysed by content analysis was used. Women reported on the aspects which were most stressful, helped them to feel more relaxed, were unexpected in some way, and also on the provision of information and on the quality of staff care.

Results. The most stressful aspects for the medical group related to the physical and emotional aspects of the process, whilst for the surgical group it concerned waiting in hospital for the operation. Whilst little was unexpected for the surgical group, many aspects came as a surprise to the medical group. Seeing the foetus was particularly difficult. All information provided was viewed as helpful, with greater information required about the phase following termination. Care from staff was rated positively, although areas for improvement in terms of opportunity to ask questions and ensuring concerns were dealt with were identified. Caring and non-judgemental staff attitudes were viewed as particularly important in helping women to feel as relaxed as possible in a potentially stressful situation.

Conclusion: Surgical termination schedules should avoid a long waiting time once the woman has been admitted. More adequate preparation is required for those having medical termination so that they have realistic expectations of what will happen, including the possibility of seeing the foetus. More attention to information about the time following termination, including possible emotional responses, is needed. The importance of positive staff attitudes in the quality of care is emphasised.
\end{abstract}

\section{Key words}

abortion, care, patient perspective, termination of pregnancy

\section{Key message points}

- Developing an understanding of how care surrounding TOP is experienced by the woman is crucial to improving services.

- Whilst the quality of care received was generally rated highly, some important issues for staff were highlighted.

- The most stressful aspects for women undergoing medical TOP related to the physical and emotional aspects of the process, whilst for those undergoing surgical TOP it related to waiting for the procedure.

- More adequate preparation is required for those undergoing medical TOP.

- More information is required about the time following TOP

- The importance of staff attitudes is emphasised.

\section{Introduction}

Termination of pregnancy (TOP) is a common procedure which is potentially very stressful. The quality of care received from staff may have important psychological implications. In many locations most TOP prior to 13 weeks gestation still involve surgical vacuum aspiration. The procedure is typically carried out on a day patient basis, is brief, but requires theatre time and usually a general anaesthetic. More recently medical terminations have been adopted not only for second trimester abortions, but also for those taking place in the early weeks of pregnancy. The medical procedure involves the patient taking oral mifepristone followed by vaginal prostaglandin 48 hours later. During the 6 hours following this administration and whilst the woman is still in hospital, the abortion typically occurs. This procedure therefore occurs over a longer period of time, but does not require surgery.

While there has been consideration of nursing staff responsibilities from the Royal College of Nursing ${ }^{1}$ and the impact of the introduction of medical termination on nursing staff welfare ${ }^{2}$ there has been little systematic study of patient needs within this area. In a recent exception to this, Maaita et $\mathrm{al}^{3}$ considered ratings of satisfaction using a 10 point visual analogue scale with various aspects of care for 100 women undergoing medical TOP. This study identified high levels of satisfaction in most areas other than provision of counselling.

Although the recent report from the Royal College of Obstetricians and Gynaecologists on setting standards for abortion care ${ }^{4}$ does include requirements for appropriate provision of information and utilisation of trained staff amongst its 50 recommendations, there is little mention of what information should be provided and the way care should be delivered. These omissions are undoubtedly due to the paucity of research on patients' perspectives on care in TOP. This paper seeks to begin to address this information vacuum.

Adequate measurement of satisfaction is complex and needs to take into account that those in receipt of any service tend to respond very positively and that the essence of satisfaction studies should be to describe the foci of any dissatisfactions occurring. ${ }^{5}$ This often means the inclusion of some qualitative analysis. Although there have been studies of patient knowledge ${ }^{6}$ and acceptability, ${ }^{7}$ little is known about the comparative nature of the experiences or the important aspects of care provision. If medical termination is to be more widely utilised, it is important that the perspectives of recipients of this service are examined. In psychological terms many aspects of medical termination may be perceived as potential stressors. It is a relatively protracted experience and can be painful, sometimes requiring the use of pethidine as well as oral analgesics. This study investigated patients' perspectives of 
each process and the care they received. These data are important in informing staff about patient needs and ensuring that services are designed to best meet these. This forms part of a wider project concerning the impact of medical and surgical procedures on emotional adjustment. ${ }^{8}$

\section{Method}

Sample

Participants were required to be experiencing a first trimester TOP not carried out because of abnormality, aged at least 16 years, and the pregnancy had not occurred as a result of assault.

For the medical termination group, women were recruited on the second visit to hospital prior to the administration of prostaglandins. The surgical group was recruited at hospital admission on the day of termination, and prior to the procedure.

The regime used for medical termination was $200 \mathrm{mg}$ of oral mifepristone followed 48 hours later by two doses of 400 $\mu \mathrm{g}$ of misoprostol given vaginally 2 hours apart. All surgical procedures were completed under general anaesthetic and patients were given $400 \mu \mathrm{g}$ of misoprostol per vaginum 2 hours pre-operatively for cervical preparation.

Women were recruited pre-termination from a consecutive sample. Forty-two (13\%) of 317 patients fulfilling criteria declined to participate. A further 67 women failed to return their assessment of care which was completed at 4 weeks post-termination. An overall response rate of $66 \%(n=208)$ of those initially eligible was achieved, with similar proportions of responders for surgical and medical terminations.

Table 1 shows characteristics of the sample and statistical comparisons between medical and surgical groups. Those having medical termination had obtained higher levels of educational qualifications. As expected, there is a clear difference between the mean weeks of gestation for the different methods (medical 6.9 weeks, surgical 9.9 weeks). Three quarters of the medical group and $23 \%$ of the surgical group reported having had some choice in procedure. Full details of the reasons for choice, where it existed, are reported elsewhere. ${ }^{8}$

Table 1 Details of sample (\% or means with standard deviations in brackets) with statistical comparisons of medical and surgical groups

\begin{tabular}{|c|c|c|c|}
\hline & Medical & Surgical & $\begin{array}{l}\mathrm{t} \text { test or chi } \\
\text { squared if } \\
\text { specified }\end{array}$ \\
\hline Age in years & $25.7(6.4)$ & $25.6(7.0)$ & Ns \\
\hline \multicolumn{4}{|l|}{ Educational qualifications: } \\
\hline None & $23 \%$ & $38 \%$ & \multirow{4}{*}{$\begin{array}{c}\text { chi squared }=18.19 \\
\quad \mathrm{df}=7, \mathrm{p}<0.001\end{array}$} \\
\hline GCSE or equivalent & $36 \%$ & $39 \%$ & \\
\hline A levels or equivalent & $27 \%$ & $22 \%$ & \\
\hline Degree & $15 \%$ & $2 \%$ & \\
\hline \multicolumn{4}{|l|}{ Marital status: } \\
\hline Married & $30 \%$ & $18 \%$ & \multirow[t]{5}{*}{ Ns } \\
\hline Single & $55 \%$ & $59 \%$ & \\
\hline Divorced & $6 \%$ & $9 \%$ & \\
\hline Separated & $3 \%$ & $4 \%$ & \\
\hline Cohabiting & $6 \%$ & $9 \%$ & \\
\hline
\end{tabular}

Ethical approval for the study was provided by the Northern General Hospital Trust Ethical Committee

\section{Procedure}

Patients' experiences of care were assessed by post at 4 weeks after the termination. This point was chosen to ensure responses were not confounded by physical sequelae of the termination, whilst minimising the retrospective nature of responses. A rating scale devised by Slade and Wills ${ }^{9}$ (Table 2), which covered aspects of the personal interaction with staff in terms of their warmth, ability to put recipients' of care at ease, dealing with issues with sensitivity, providing opportunities for questions and clear and comprehensible information, was used. In addition, a series of open questions about important aspects of the process were included to access both positive and negative components of the experience. These covered the following:

- the most stressful aspects of the termination

- factors which made the experience more and less stressful respectively

- any unexpected aspects of the process

- responses to seeing the foetus for the medical group

- views about the adequacy of information provision relating to the hospital stay and concerning the time at home after the termination.

Table 2 Provision of care in TOP

\begin{tabular}{|c|c|c|}
\hline 1) & I felt the staff were: & \\
\hline a) & Very cool and distant & [ ] \\
\hline b) & Cool and distant & [ ] \\
\hline c) & Warm and friendly & [ ] \\
\hline d) & Very warm and friendly & [ ] \\
\hline 2) & I felt the staff: & \\
\hline a) & Put me very much at my ease & [ ] \\
\hline b) & Put me at my ease & [ ] \\
\hline c) & Made me feel slightly uncomfortable & [ ] \\
\hline d) & Made me feel very uncomfortable & [ ] \\
\hline 3) & The staff dealt with personal issues: & \\
\hline a) & Very sensitively & [ ] \\
\hline b) & Quite sensitively & [ ] \\
\hline c) & Quite insensitively & [ ] \\
\hline d) & Very insensitively & [ ] \\
\hline 4) & The staff: & \\
\hline a) & Gave me plenty of opportunity to ask questions & [ ] \\
\hline b) & Gave me some opportunity to ask questions & [ ] \\
\hline c) & Gave me little opportunity to ask questions & [ ] \\
\hline d) & Gave me no opportunity to ask questions & [ ] \\
\hline 5) & The staff: & \\
\hline a) & Gave me information in a way which was clear to me & {$[$ ] } \\
\hline b) & $\begin{array}{l}\text { Gave me some information which was clear and some which } \\
\text { I did not understand }\end{array}$ & {[} \\
\hline c) & Gave me information which was not clear to me at all & [ ] \\
\hline 6) & The staff: & \\
\hline a) & $\begin{array}{l}\text { Were willing to listen to any concerns I had about my } \\
\text { termination }\end{array}$ & [ ] \\
\hline b) & $\begin{array}{l}\text { Did not give me enough chance to talk about any concerns I } \\
\text { had about my termination }\end{array}$ & {$[$ ] } \\
\hline 7) & The staff: & \\
\hline a) & Seemed to talk down to me & [ ] \\
\hline b) & Talked to me as an equal & [ ] \\
\hline
\end{tabular}

Analyses

Qualitative information was analysed according to the procedure outlined by Dey. ${ }^{10}$ Categories of responses are identified and individual responses are allocated to those categories. In all cases this procedure was carried out by the first author and then the allocation completed again independently by the third author. The first rater's categorisation was replicated on $92 \%$ and $94 \%$ of occasions for the medical and surgical groups, respectively, indicating an acceptable level of reliability for this process. 


\section{Results}

Quality of care provided by staff was viewed very favourably. Patients perceived staff as warm and friendly (medical (M) 90\%, surgical (S) 82\%), putting women at their ease (M 93\%, S 90\%) and dealing with issues at least quite sensitively (M 91\%, S 93\%). Sixty percent in both groups felt they had plenty of opportunity to ask questions with a further $30 \%$ in each group reporting some opportunity. Eighty-three percent and $86 \%$, respectively, felt that all the information they had been given was clear. Eighty-five percent and $88 \%$, respectively, felt that staff had been willing to listen to their concerns and the majority that staff had talked with them as an equal (M 90\%, S $86 \%$ ).

The responses to the open questions are shown in Tables 3-9. The percentage of participants reporting each category is indicated. The totals do not add to $100 \%$ as individuals might indicate more than one category of response, and groupings with less than $5 \%$ are not reported.

The most stressful aspect of having a termination (Table 3) Whilst almost all the medical group (93\%) were able to specify a most stressful aspect, this applied to only two thirds $(68 \%)$ of the surgical sample. For the medical group aspects relating to the physical (pain and bleeding) and emotional experience of the process were most frequently cited $(27 \%)$, followed by actually seeing the foetus $(20 \%)$.

The main stressor for the surgical group appeared to be waiting in hospital for the operation, which can extend to several hours. The actual process of being wheeled down to theatre, waiting outside theatre and receiving the anaesthetic were particularly identified. A small group found it difficult immediately on 'coming round'. Another set of concerns included focusing on the reality of what was happening, and fears of the emotional consequences.

Table 3 The most stressful aspects

\begin{tabular}{|c|c|}
\hline Medical & \\
\hline None or none specified & $7 \%$ \\
\hline $\begin{array}{l}\text { Physical and emotional aspects of the process } \\
\text { The experience of pain/bleeding/feeling what was happening } \\
\text { and its meaning/emotions during the process }\end{array}$ & $27 \%$ \\
\hline $\begin{array}{l}\text { The foetus } \\
\text { Waiting for the foetus/expelling or having the foetus removed } \\
\text { /seeing the foetus/leaving foetus. }\end{array}$ & $20 \%$ \\
\hline $\begin{array}{l}\text { Waiting } \\
\text { Waiting (unspecified)/before and between tablets and } \\
\text { pessaries/in hospital for the process to start/for confirmation of } \\
\text { completion/to go home }\end{array}$ & $18 \%$ \\
\hline $\begin{array}{l}\text { Hospital environment and process of care } \\
\text { Lack of privacy/having internal examinations or scan/going to } \\
\text { toilet to collect products to show nurses/being or feeling alone }\end{array}$ & $16 \%$ \\
\hline $\begin{array}{l}\text { Lack of certainty } \\
\text { Not knowing what to expect worrying it might fail }\end{array}$ & $14 \%$ \\
\hline Surgical & \\
\hline None or none specified & $32 \%$ \\
\hline $\begin{array}{l}\text { The process on the day } \\
\text { Waiting to go to theatre/going to theatre/waiting for or having } \\
\text { the anaesthetic or needle/coming round after the operation. }\end{array}$ & $45 \%$ \\
\hline $\begin{array}{l}\text { The decision and its consequences } \\
\text { Facing the reality of what was being done/uncertainty about } \\
\text { whether the right decision/fear about how may feel after. }\end{array}$ & $13 \%$ \\
\hline Waiting (unspecified) & $9 \%$ \\
\hline
\end{tabular}

Factors which were felt to make the process more stressful than necessary (Table 4)

One third of each sample identified aspects of the process which they felt were more stressful than necessary, and a wide variety of different concerns were identified. Many of the issues could not be easily eliminated. However, there is perhaps an issue about privacy for some, and the importance of staff being non-judgmental is emphasised. There is a frequent concern in the surgical group about being admitted early in the morning and then having to wait a long time for the operation. As this has already been identified as one of the most stressful aspects for the surgical group, there is a question as to whether staggered admission times reflecting theatre order is a practical proposition.

Table 4 Aspects that made the experience more stressful than necessary

\begin{tabular}{|lr|}
\hline \multicolumn{1}{|c|}{ Medical } & $67 \%$ \\
None or none specified & $6 \%$ \\
$\begin{array}{l}\text { Aspects of staff behaviour } \\
\text { Lack of support or help, feeling criticised/care being too clinical. } \\
\text { Things not going as planned }\end{array}$ & $\mathbf{6 \%}$ \\
$\begin{array}{l}\text { Having to stay in overnight/process not working } \\
\text { None or none specified } \quad \text { Surgical }\end{array}$ & $\mathbf{6 8 \%}$ \\
Waiting on the ward for the operation (often for several hours) & $\mathbf{1 6 \%}$ \\
$\begin{array}{l}\text { Aspects of staff behaviour } \\
\text { Nursing staff attitudes and or behaviours/doctors attitudes and or } \\
\text { behaviours }\end{array}$ & $\mathbf{7 \%}$ \\
\hline
\end{tabular}

Factors which helped patients to feel more relaxed about the process (Table 5)

The most important aspect related to staff attitudes and behaviours. The main difference between the groups is that having the presence of someone the woman is already close to is more frequently mentioned as helpful in the medical group, possibly because it is experienced as a more stressful process. ${ }^{7}$

Table 5 Aspects of process that helped with feeling more relaxed

\begin{tabular}{|c|c|}
\hline $\begin{array}{l}\text { Medical } \\
\text { Aspects of the staff attitudes and behaviours } \\
\text { Friendliness, helping the woman to feel relaxed and at ease, } \\
\text { being sympathetic, kind, non-judgmental, caring, helpful, } \\
\text { showing interest in you as a person. }\end{array}$ & $60 \%$ \\
\hline $\begin{array}{l}\text { The process being a shared experience } \\
\text { Boyfriend/husband/friend/family member allowed to stay/other } \\
\text { patients going through the same. }\end{array}$ & $23 \%$ \\
\hline None or none specified & $18 \%$ \\
\hline 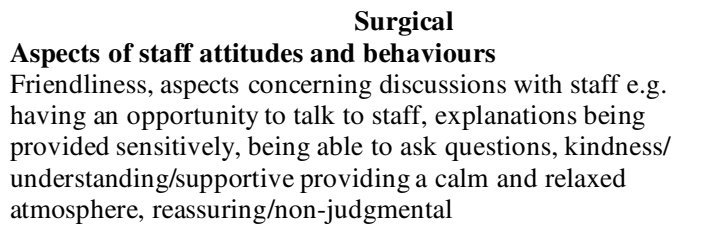 & $61 \%$ \\
\hline $\begin{array}{l}\text { It being a shared experience } \\
\text { Presence of partner/friend/being with other women in the same } \\
\text { situation }\end{array}$ & $14 \%$ \\
\hline None or none specified & $20 \%$ \\
\hline
\end{tabular}

Unexpected aspects of the experience (Table 6)

When unexpected events occur and the person has been unable to prepare for them, they are often experienced as 
more stressful. Whilst $85 \%$ of the surgical sample reported that nothing that happened was unexpected, this was the case for only half of the medical group, suggesting that experiences matched expectations much more closely in the former group. Some aspects of the experience i.e. the degree of pain and the scale of the bleeding, were unexpected by the medical group. It is also clear that the outcome for the medical termination was less certain. For the surgical group no unexpected aspect reached $5 \%$.

Table 6 Anything that happened that was unexpected

\begin{tabular}{|lc|}
\hline \multicolumn{1}{c}{ Medical } & $\mathbf{5 1 \%}$ \\
No or none specified & $\mathbf{2 0 \%}$ \\
$\begin{array}{l}\text { Aspects of the experience } \\
\text { Degree of pain/scale of bleeding and clots/physical responses } \\
\text { (dizziness/sickness/diarrhoea)/physical process worse than } \\
\text { expected. }\end{array}$ & $\mathbf{1 1 \%}$ \\
$\begin{array}{l}\text { The outcome not being as predicted } \\
\text { The termination process not being completed/needing an } \\
\text { operation/haemorrhaging needing transfusion/passing no or } \\
\text { two sacs. }\end{array}$ & $\mathbf{5 \%}$ \\
Seeing, recognising or size of foetus & \\
\hline
\end{tabular}

The impact of seeing the foetus (Tables $7 a$ and $7 b$ )

A significant proportion of the women $(n=59,56 \%)$ having a medical termination saw what they believed to be the foetus intact. This question concerns their response to this experience. For the remainder who had no direct contact with the foetus, their feelings about this fact were elicited. Seeing the foetus, in general, appears to be a difficult aspect of the medical termination process which can be distressing, bring home the reality of the event and may influence later emotional adaptation. ${ }^{7}$ When women have not seen anything clearly definable, then the majority are relieved about this, feeling that they have avoided a potentially traumatic aspect of the experience. Positive responses to seeing the foetus or disappointment at having missed this are relatively uncommon, but do occur.

Table 7a Response to seeing the foetus for the medical group

\begin{tabular}{lc}
$\begin{array}{l}\text { Strong negative feelings } \\
\text { Upset distressed, awful/sadness/shocked/scared or disturbed. }\end{array}$ & $\mathbf{5 1 \%}$ \\
$\begin{array}{l}\text { Strong negative feelings directed at herself } \\
\text { Guilt/shame or anger }\end{array}$ & $\mathbf{1 4 \%}$ \\
Mild negative feelings & $\mathbf{5 \%}$ \\
$\begin{array}{l}\text { Neutral or no feelings } \\
\text { Curious/surprised }\end{array}$ & $\mathbf{1 0 \%}$ \\
$\begin{array}{l}\text { Positive feelings } \\
\text { Relieved/privileged }\end{array}$ & $\mathbf{5 \%}$ \\
$\begin{array}{l}\text { Influence on perception of event } \\
\text { Made it more real/question what doing }\end{array}$ & $\mathbf{5 \%}$ \\
$\begin{array}{l}\text { Actively tried to distance self } \\
\text { Like a picture/not think of as a baby/like heavy period/clot }\end{array}$ & $\mathbf{7 \%}$ \\
$\begin{array}{l}\text { Longer term impact on feelings } \\
\text { Can't forget image/thought about it later/helped me to adapt }\end{array}$ & $\mathbf{8 \%}$ \\
\hline
\end{tabular}

\section{Information provision (Tables 8 and 9)}

Participants were asked whether there was any additional information which might have been helpful about their time in hospital or the time after. They were also asked whether
Table 7b Responses for the medical group about not seeing the foetus

\begin{tabular}{|lc|}
\hline No response reported & $\mathbf{2 8 \%}$ \\
$\begin{array}{l}\text { Positive response } \\
\text { Glad, pleased, relieved/seeing it would be worse, more } \\
\text { traumatic or upsetting/did not want to see. }\end{array}$ & $\mathbf{6 6 \%}$ \\
$\begin{array}{l}\text { Negative response } \\
\text { Longer to accept a lost baby/feel never been pregnant/curious } \\
\text { would have been interesting /worried abortion not worked. }\end{array}$ & $\mathbf{1 5 \%}$ \\
\hline
\end{tabular}

any information which was provided was unhelpful. Although approximately $40 \%$ in the medical group did want further information, there was little consistency in terms of the identified issues. It is therefore difficult to make any specific service recommendations on this aspect of care, other than allocating sufficient time for individuals to raise their own queries with staff. While the medical group has a requirement for more information about what would be happening, requests for additional information in the surgical group were very uncommon.

Table 8 Any additional information which women would have found helpful about their time in hospital?

\begin{tabular}{|c|c|}
\hline Medical & \\
\hline No or none specified & $\mathbf{5 8 \%}$ \\
\hline $\begin{array}{l}\text { About the foetus } \\
\text { That might see foetus/what foetus or womb contents would } \\
\text { look like/what happens to foetus after. }\end{array}$ & $12 \%$ \\
\hline $\begin{array}{l}\text { Aspects of the experience } \\
\text { Timing and amount of bleeding/what it would feel like } \\
\text { physically and emotionally/degree of pain. }\end{array}$ & $11 \%$ \\
\hline $\begin{array}{l}\text { Information about the procedures and medication } \\
\text { What pain killers were/possible side effects/information on } \\
\text { details of procedures/others. }\end{array}$ & $9 \%$ \\
\hline $\begin{array}{l}\text { About timing } \\
\text { How long the process would take/how long in hospital }\end{array}$ & $7 \%$ \\
\hline $\begin{array}{l}\text { Particular medical outcomes } \\
\text { Could abort before pessaries/could be complications/become } \\
\text { ill/could need an operation. }\end{array}$ & $6 \%$ \\
\hline
\end{tabular}

Information provision about the time after the termination was also seen as satisfactory by the majority, and no information which was provided was viewed as unhelpful. There was, however, a need for greater information provision about emotional issues, in particular the range of possible normal experiences following the process. The second point for both groups concerned uncertainties about when symptoms such as pain or bleeding occurring in the aftermath of termination had reached a duration or intensity indicating that help should be sought.

\section{Discussion}

Whilst the quality of care received was generally rated very highly, these findings do highlight some important issues for staff in TOP services. It is unsurprising that the aspects which promote more beneficial experiences related clearly to positive non-judgmental attitudes and behaviours from staff. However, the availability of support from others was also important, particularly in the medical group where the process may be quite protracted. There were concerns from some women about the lack of privacy in hospital, but some noted the benefits of contact with the others going through the same experience. It is important for services to have the 
Table 9 Anything about the time after the termination that it would have been helpful to know that they were not told.

\begin{tabular}{|lc|}
\hline \multicolumn{1}{|c}{ Medical } & $\mathbf{7 6 \%}$ \\
No or none stated & $\mathbf{1 4 \%}$ \\
$\begin{array}{l}\text { About emotional issues } \\
\text { how they might feel or think/access numbers for emotional }\end{array}$ & $\mathbf{8 \%}$ \\
$\begin{array}{l}\text { Other experiences afterwards } \\
\text { Need to rest or possibility of feeling tired/the degree of pain } \\
\text { and help identifying when this is abnormal/amount and } \\
\text { duration of bleeding }\end{array}$ & \\
& $\mathbf{6 6 \%}$ \\
No or none stated & $\mathbf{1 9 \%}$ \\
$\begin{array}{l}\text { About emotional issues } \\
\text { How they would feel/how to cope with feelings or contact for } \\
\text { counselling }\end{array}$ & $\mathbf{6 \%}$ \\
$\begin{array}{l}\text { Knowledge about physical aspects } \\
\text { Degree of pain and bleeding /when the body would return to } \\
\text { normal }\end{array}$ &
\end{tabular}

flexibility and resources to identify and to meet diverse needs in the provision of care.

It is disappointing that $6-7 \%$ of patients expressed concerns about specific staff behaviours. Patients are cared for in a separate part of the gynaecology ward by a specific group of highly trained and motivated nurses who have chosen to input to the service. Additionally, $40 \%$ of women reported only 'some' or 'less' opportunity to ask questions, suggesting that more opportunity might have been helpful, and one in seven women felt staff had not been willing to listen to their concerns. This emphasises the difficulties staff may have in providing service to patients in a stressful situation, but also indicates the need for continued training input to ensure that the culture within a ward supports appropriate standards of interpersonal interaction.

As well as identifying more significant stressors and unexpected parts of the experience, the medical group was also more likely to identify gaps in information provision. There is therefore coherence about these findings which suggests that staff need to ensure that they are providing sufficient and appropriate information to enable patients to develop realistic expectations about pain and bleeding duration, together with the probability that the patient may see an identifiable foetus. While information outlining the process of medical termination was routinely given at an early stage when decisions about termination were being addressed, it is clear this was inadequate. A new information leaflet has now been developed to address the issues relating to pain, bleeding and seeing the foetus more explicitly.

In the case of surgical terminations it would probably be helpful if admission times could be staggered in order that the wait for the operation, which is identified as one of the most significant stressors, is reduced. There are limitations, however, to the degree of change, in that women must attend early enough to receive the pre-treatment with prostaglandins and pre-operative assessment by anaesthetist and surgeon.

There was evidence to suggest that more information needed to be given in preparation for possible emotional responses following the termination. Women also had difficulty in deciding when the physical consequences of the termination, in particular the duration and extent of bleeding and pain, exceeded what might be considered as normal after a medical termination and required consultation. It should be noted that women rarely stated that too much information was provided at any stage of the process.

The experience of care is likely to have influence upon emotional adaptation following TOP and it is important that services consider how they can best meet the needs of these patient groups. The RCOG evidence based clinical guidelines on the care for women requesting induced abortion $^{4}$ are to be reviewed in 2 years. It is to be hoped that this information can contribute to the knowledge base to enable recommendations based upon patient perspectives of care to feature more strongly in the future.

\section{Statements on funding and competing interests}

Funding. None declared.

Competing interests. None declared.

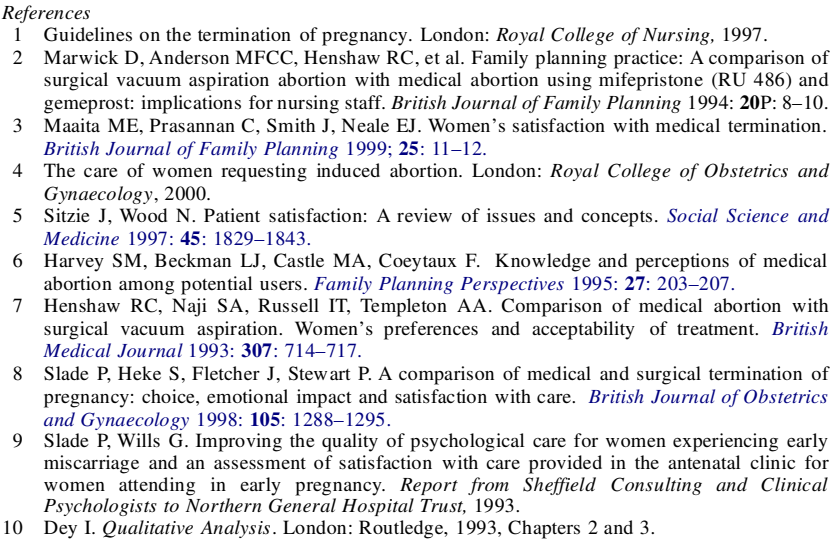

4 The care of women requesting induced abortion. London: Royal College of Obstetrics and Gynaecology, 2000.

Wood N. Patient satisfaction: A review of issues and concepts. Social Science and Medicine 1997: 45: 1829-1843.

Harvey SM, Beckman LJ, Castle MA, Coeytaux F. Knowledge and perceptions of medica abortion among potential users. Family Planning Perspectives 1995: 27: 203-207.

Henshaw RC, Naji SA, Russell IT, Templeton AA. Comparison of medical abortion with surgical vacuum aspiration. Women's preferences and acceptability of treatment. British Medical Journal 1993: 307: 714-717.

8 Slade P, Heke S, Fletcher J, Stew art P. A comparison of medical and surgical termination of pregnancy: choice, emotional impact and satisfaction with care. British Journal of Obstetrics and Gynaecology 1998: 105: 1288-1295.

9 Slade P, Wills G. Improving the quality of psychological care for women experiencing early miscarriage and an assessment of satisfaction with care provided in the antenatal clinic for women attending in early pregnancy. Report from Sheffield Consulting and Clinical chersts to Northern General Hospital Trust, 1993.

10 Dey I. Qualitative Analysis. London: Routledge, 1993, Chapters 2 and 3. 